\title{
Evaluation of Bosch-Based Systems Using Non-Traditional Catalysts at Reduced Temperatures
}

\author{
Morgan B. Abney ${ }^{1}$ and J. Matthew Mansell ${ }^{2}$ \\ NASA Marshall Space Flight Center, Huntsville, AL, 35812
}

\begin{abstract}
Oxygen and water resupply make open loop atmosphere revitalization (AR) systems unfavorable for long-term missions beyond low Earth orbit. Crucial to closing the AR loop are carbon dioxide reduction systems with low mass and volume, minimal power requirements, and minimal consumables. For this purpose, NASA is exploring using Boschbased systems. The Bosch process is favorable over state-of-the-art Sabatier-based processes due to complete loop closure. However, traditional operation of the Bosch required high reaction temperatures, high recycle rates, and significant consumables in the form of catalyst resupply due to carbon fouling. A number of configurations have been proposed for next-generation Bosch systems. First, alternative catalysts (catalysts other than steel wool) can be used in a traditional single-stage Bosch reactor to improve reaction kinetics and increase carbon packing density. Second, the Bosch reactor may be split into separate stages wherein the first reactor stage is dedicated to carbon monoxide and water formation via the reverse water-gas shift reaction and the second reactor stage is dedicated to carbon formation. A series system will enable maximum efficiency of both steps of the Bosch reaction, resulting in optimized operation and maximum carbon formation rate. This paper details the results of testing of both single-stage and two-stage Bosch systems with alternative catalysts at reduced temperatures. These results are compared to a traditional Bosch system operated with a steel wool catalyst.
\end{abstract}

\section{Nomenclature}

$B$-CaTS $=$ Bosch Catalyst Test Stand

$C(s) \quad=$ Solid Carbon

$C D R A=$ Carbon Dioxide Removal Assembly

$\mathrm{CH}_{4} \quad=$ Methane

$\mathrm{CO}=$ Carbon Monoxide

$\mathrm{CO}_{2}=$ Carbon Dioxide

$\mathrm{Co}-\mathrm{Al}=$ Cobalt on Aluminum Catalyst

$\mathrm{Co}-\mathrm{Sh}=$ Cobalt Shavings Catalyst

$C R A=$ Carbon Dioxide Reduction Assembly

$\mathrm{H}_{2} \quad=$ Hydrogen

$\mathrm{H}_{2} \mathrm{O}=$ Water

$I S S=$ International Space Station

$M S F C=$ Marshall Space Flight Center

$\mathrm{Ni}-\mathrm{Al}=\mathrm{Nickel}$ on Aluminum Catalyst

$\mathrm{Ni}-\mathrm{Cu}=\mathrm{Nickel}$ on Copper Catalyst

$\mathrm{Ni}-\mathrm{Sh} \quad=$ Nickel Shavings Catalyst

$N i F-A=$ Nickel Foam A Catalyst

$N i F-B=$ Nickel Foam B Catalyst

$N i W-A=$ Nickel Wool A Catalyst

${ }^{1}$ Aerospace Engineer, Environmental Control and Life Support Systems Development Branch, Bldg 4755 Room 403-7, Huntsville, AL 35812, AIAA Member.

${ }^{2}$ Test Engineer, Environmental Control and Life Support Systems Development Branch, Bldg 4755 Room 115, Huntsville, AL 35812. 
$\mathrm{NiW}-\mathrm{B}=$ Nickel Wool B Catalyst

$O G A=$ Oxygen Generation Assembly

RWGS = Reverse Water-Gas Shift

$S O A=$ State-of-the-Art

$S W-S=$ Shredded Steel Wool Catalyst

$S W-W \quad=$ Wound Steel Wool Catalyst

$\mu G C=$ Micro-Gas Chromatograph

\section{Introduction}

$\mathrm{T}$ he complexity of spacecraft life support systems is highly dependent on a number of factors including the number of crew, the duration of the mission, the destination of the mission, etc. For very short-term missions, it may be feasible to bring all necessary air and water, discard all metabolic waste products, and return before resupply is necessary. However, as mission duration is extended, crew size is increased, and destinations far beyond low earth orbit are pursued, life support systems with maximum mass recovery become essential. State-of-the-art oxygen recovery technology produces the byproduct methane, which is vented. Most of the hydrogen bound in the vented methane must be resupplied in order to sustain the process. In an effort to avoid this mass penalty, NASA continues to pursue Bosch technology development. The byproduct of the Bosch reaction is elemental carbon. Thus, the theoretical hydrogen loss is zero. However, typical Bosch systems have a number of drawbacks, including high reactor temperature and pressure and low single-pass conversions. A potential improvement to the process is to utilize two reactors in a series configuration, with the reactors optimized for different component reactions. This paper discusses the recent efforts toward development of a series-Bosch system, including the results of Reverse Water-Gas Shift (RWGS) equilibrium experiments and a carbon formation experiment.

\section{Background}

Prior to the International Space Station (ISS), life support systems for all NASA missions involved bringing air and water, discarding metabolic waste products, and returning before resupply was necessary. Oxygen was stored in tanks as a compressed gas or supercritical fluid and metered into habited zones as needed. ${ }^{1}$ For the Mercury, Gemini, Apollo and Space Shuttle systems, metabolic $\mathrm{CO}_{2}$ was removed from the cabin through the use of replaceable lithium hydroxide canisters. Similarly, liquid-phase metabolic wastes (urine, sweat, etc.) were simply removed from the cabin, and the equivalent fresh water was replaced from storage tanks. As life support systems developed, regenerable systems became superior to those basic systems. Skylab was equipped with regenerable molecular sieves (zeolite 5A and 13X) for $\mathrm{CO}_{2}$ removal. This was the pre-cursor to the state-of-the-art (SOA) ISS Carbon Dioxide Removal Assembly (CDRA) that uses the same zeolites to remove $\mathrm{CO}_{2}$. As NASA prepares for missions beyond low-earth-orbit, the recovery of oxygen from $\mathrm{CO}_{2}$ becomes more advantageous. For this purpose, the Carbon Dioxide Reduction Assembly (CRA) was developed and tested in conjunction with Hamilton Sundstrand..$^{2-5}$ The CRA was delivered to ISS in April 2010 and activated in August 2010. The system operates in a $\mathrm{CO}_{2}$-rich environment due to limited availability of hydrogen from the the Oxygen Generation Assembly (OGA). Thus, oxygen recovery is dependent on available hydrogen. A key development requirement of the CRA was greater-than- $45 \%$ recovery of available hydrogen as water (theoretical maximum being 50\%). Assuming minimum acceptable hydrogen conversion, $\mathrm{CO}_{2}$ conversion is $\sim 78.75 \%$. The unreacted $\mathrm{CO}_{2}$ is vented overboard along with the CRA product methane $\left(\mathrm{CH}_{4}\right)$. This loss of direct oxygen, in the form of $\mathrm{CO}_{2}$, and indirect oxygen, in the form of methane-bound hydrogen, results in a total loss of $\sim 172 \mathrm{~kg}(378 \mathrm{lb})$ oxygen per crew member per year - a considerable improvement over the mass balance in the absence of the CRA, which results in a loss of $\sim 299 \mathrm{~kg}$ (657 lb) oxygen per crew member per year. However, considering the loss of $3 / 4$ of a ton of oxygen per year for a crew of four, it is clear that additional oxygen recovery is desirable. If CRA technology is to be used on future missions, additional recovery will require hydrogen-rich operation and additional subsystems to recover hydrogen from methane. Each additional system adds mass, volume, and power to the architecture. As an alternative to an ISSbased oxygen recovery system, future missions may turn to a Bosch system.

Bosch technology has been explored by NASA since the early 1960 's. ${ }^{6}$ In the early 1970 's, a system sized for a three-person crew was developed and tested by the General Dynamics Corporation. ${ }^{7}$ Development was continued by Life Sciences, Inc. into the 1980's and 1990's until a comparative test was completed at Marshall Space Flight Center (MSFC) to down-select a technology for Space Station Freedom. ${ }^{8}$ The Sabatier-based system was ultimately chosen. The assessment shown in Table 1 was provided in the final report of the testing. When the technology was originally assessed, the only strength credited to the Bosch was complete oxygen and hydrogen recovery, a feature that makes the Bosch an ever more desirable technology as longer-duration spaceflights are considered. Multiple 
Table 1. Assessment from NASA's Sabatier/Bosch 1990's comparative test. ${ }^{8}$

\begin{tabular}{|c|c|c|}
\hline System & Bosch & Sabatier \\
\hline \multirow{2}{*}{$\begin{array}{l}\text { Major } \\
\text { Strengths }\end{array}$} & \multirow{2}{*}{ Complete $\mathrm{O}_{2}$ Loop Closure } & High technical maturity \\
\hline & & Low complexity \\
\hline \multirow{3}{*}{$\begin{array}{l}\text { Minor } \\
\text { Strengths }\end{array}$} & & No regular maintenance \\
\hline & & Reliability \\
\hline & & Ease of integration \\
\hline \multirow{4}{*}{$\begin{array}{l}\text { Major } \\
\text { Weaknesses }\end{array}$} & Difficulty in packaging & \multirow{2}{*}{ Impacts to IWGS* } \\
\hline & Major design revisions needed for flight & \\
\hline & Carbon formation in undesirable locations & \multirow{2}{*}{ Water carryover from separator } \\
\hline & Could not achieve 8-man rate & \\
\hline \multirow{4}{*}{$\begin{array}{l}\text { Minor } \\
\text { Weaknesses }\end{array}$} & Regular maintenance required & \multirow{2}{*}{ Incomplete $\mathrm{O}_{2}$ loop closure } \\
\hline & Low reliability & \\
\hline & More complex integration & \multirow{2}{*}{ Possible external contamination concern } \\
\hline & Carbon contamination in the recycle loop & \\
\hline
\end{tabular}

*IWGS = Integrated Waste Gas System

weaknesses were identified for Bosch with most attributed directly to system design. Closer inspection of these weaknesses provides clear areas for Bosch improvement if a Bosch-based system will ever be competitive with Sabatier-based systems. The "difficulty in packaging" was explained as "extreme difficulty in packing the subsystem in the air revitalization rack, especially in light of the calculated expected flight size..." Thus, a very large system was to be required for on-orbit implementation. The Bosch tested in this report operated at above-ambient pressures. To prevent out-gassing of harmful components (i.e. carbon monoxide and hydrogen), a vacuum dome was fabricated around the reactor. Operation at pressures below that of the surrounding spacecraft environment would eliminate the need for a vacuum dome and dramatically decrease the volume and mass of the system. Additionally, the Bosch system had a very low single-pass conversion (6-7\%), requiring substantial volume, mass, and energy be committed to equipment for pumping high flow rates of gas. Modifying the Bosch design to maximize single-pass conversion will decrease those requirements. Catalyst cartridge resupply was necessary due to the production of carbon. The use of catalysts which exhibit sufficiently high activity at higher carbon density, as well as methods of removal of product carbon from the reactor, may dramatically improve the launch mass and maintenance time. Finally, high temperature operation of the system contributed to a high power requirement. Optimizing the system to maximize the use of available energy will bring the Bosch closer to being truly competitive with other $\mathrm{CO}_{2}$ reduction technologies. With the history of Bosch technology laying a clear foundation for potential improvements, NASA is again pursuing the development of a Bosch-based system.

Rather than a single reaction, the Bosch process is a combination of multiple reactions including the Reverse Water-Gas Shift (RWGS) reaction, a carbon monoxide hydrogenation reaction, and the Boudouard reaction, as shown in equations 1-4 below.

RWGS:

CO Hydrogenation:

Boudouard:

Overall Bosch:

$$
\mathrm{CO}_{2}+\mathrm{H}_{2} \leftrightarrow \mathrm{H}_{2} \mathrm{O}+\mathrm{CO}
$$$$
\mathrm{CO}+\mathrm{H}_{2} \leftrightarrow \mathrm{H}_{2} \mathrm{O}+\mathrm{C}(\mathrm{s})
$$$$
2 \mathrm{CO} \leftrightarrow \mathrm{CO}_{2}+\mathrm{C}(\mathrm{s})
$$$$
\mathrm{CO}_{2}+\mathrm{H}_{2} \leftrightarrow \mathrm{H}_{2} \mathrm{O}+\mathrm{C}(\mathrm{s})
$$

Previous Bosch test systems involved a single reactor operated at $\sim 203 \mathrm{kPa}(29 \mathrm{psi})$ and $\sim 650^{\circ} \mathrm{C}\left(1200^{\circ} \mathrm{F}\right)$. These conditions were chosen in an attempt to maximize the water production rate. This led to the selection of conditions somewhere between the optimum for any of the individual reactions and proved to be highly inefficient due to thermodynamic differences between the RWGS reaction and the carbon formation reactions. As seen in Figure 1, the RWGS reaction is endothermic, while the two carbon formation reactions are exothermic. Additionally, a plot of 
the Gibbs energies versus temperature indicates that, at the operating temperature of $650^{\circ} \mathrm{C}$, the RWGS does not favor products, and the carbon formation reactions favor products only slightly. By separating these two steps of the Bosch process, it may be possible to optimize reactors and maximize the single-pass efficiency of the process.

For the RWGS reaction, lower pressures and higher temperatures are thermodynamically favorable and lead to increased equilibrium conversion, as demonstrated by the Gibbs energies and equilibrium constants shown in Figure 2 and 3, respectively. However, if the pressure is lowered sufficiently, the temperature may also be lowered and still provide better performance than the traditional Bosch reactor. This would potentially allow for lower power requirements and recycle rates. For the Boudouard and $\mathrm{CO}$ hydrogenation reactions, lower pressures and lower temperatures are thermodynamically favorable and lead to increased equilibrium conversion. Additionally, the carbon formation reactions are not influenced as dramatically by pressure as the RWGS. Rather, the carbon formation reactions are greatly influenced by temperature. In the ISS CRA, the Sabatier reactor provides enough heat at the inlet to initiate the exothermic reaction. The remaining length of the reactor is cooled to provide a decreasing temperature gradient that maximizes conversion. A similar design can be used for a carbon formation reactor to maximize product carbon. This will result in a lower power requirement and potentially a mass and volume savings by reducing the required recycle rate.

Regardless of the equilibrium considerations of a system, if the reaction rate is too slow, it cannot be used in a practical application. It is well known from the Arrhenius equation that lowering the temperature of a reaction will lower the rate constant, thus decreasing the reaction rate. However, experimental data is needed to determine how the reaction rates of both the RWGS and carbon formation reactions will respond to changes in pressure and whether utilizing a system with two reactors operating at different pressure and/or temperature will result in a significant improvement over the single-reactor system.

An additional consideration that must be taken into account for a carbon formation reactor is that of controlling solid carbon formation. It is clear that catalysts with higher

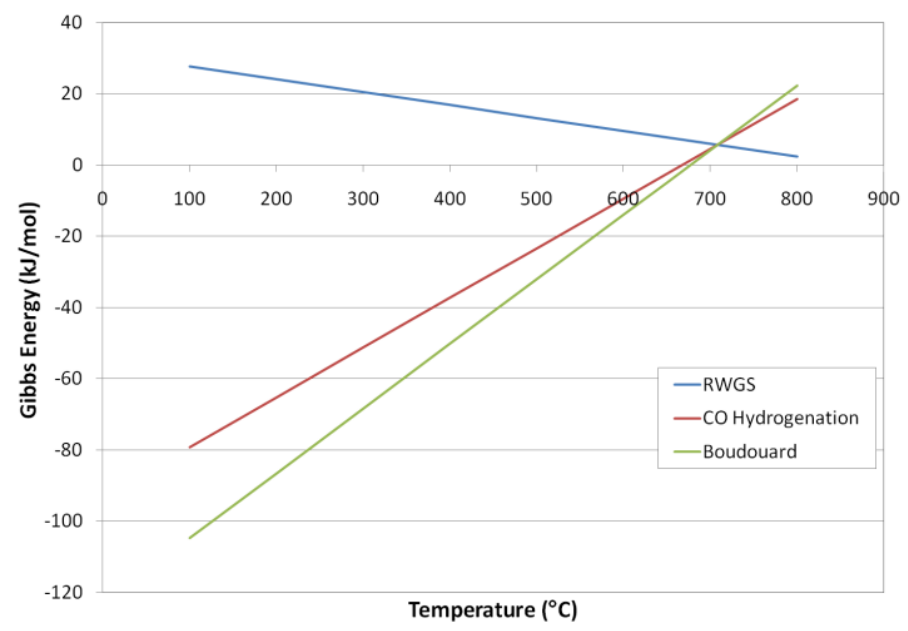

Figure 1. Estimated Gibbs energy of Bosch reactions at 202 kPa.

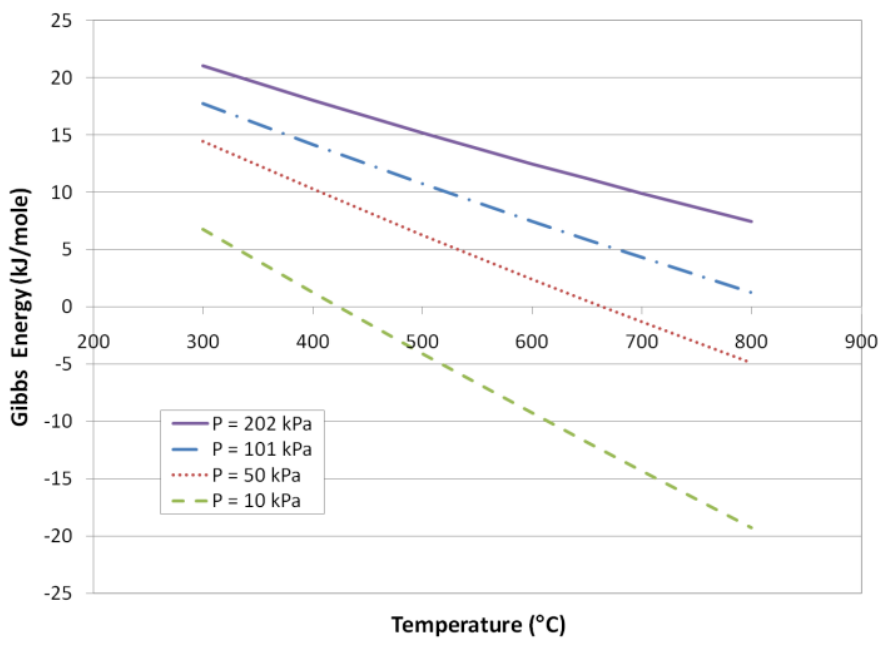

Figure 2. Estimated Gibbs energy of the RWGS reaction at multiple pressures.

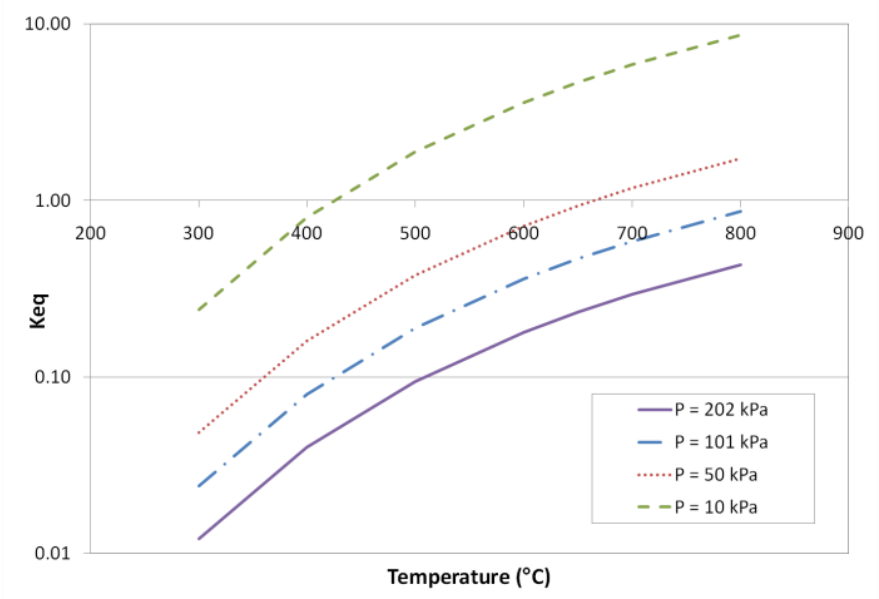

Figure 3. Equilibrium constants for RWGS reaction at multiple temperatures and pressures.

American Institute of Aeronautics and Astronautics 
specific carbon density will result in a modest decrease in Bosch resupply requirements. However, identification of a regenerable catalyst or development of a system that forms carbon on surfaces other than the catalyst will dramatically improve the long-term viability of a Bosch system. Although these types of carbon formation improvements are of interest to NASA, they will not be addressed in this effort.

\section{Materials and Methods}

The Bosch Catalyst Test Stand (B-CaTS) was built in 2009 to provide a sub-scale reactor system for catalyst testing. The B-CaTS was modified into a series-reactor system in 2011 to assist in Series-Bosch testing. The two test stands are described below along with testing materials and methods.

\section{A. B-CaTS and Series B-CaTS}

The B-CaTS, shown schematically in Figure 4, is composed of gas sources, a single reactor assembly, and various control and instrumentation components (i.e. flow controllers, solenoid valves, thermocouples, etc.). An Agilent Technology micro-gas chromatograph $(\mu \mathrm{GC})$ is used to analyze the gas composition at multiple points in the system. The sampling point is selected with a 10-port valve controlled by the system software. The system is controlled using LabView with data collected by a NASA application called PACRATS.

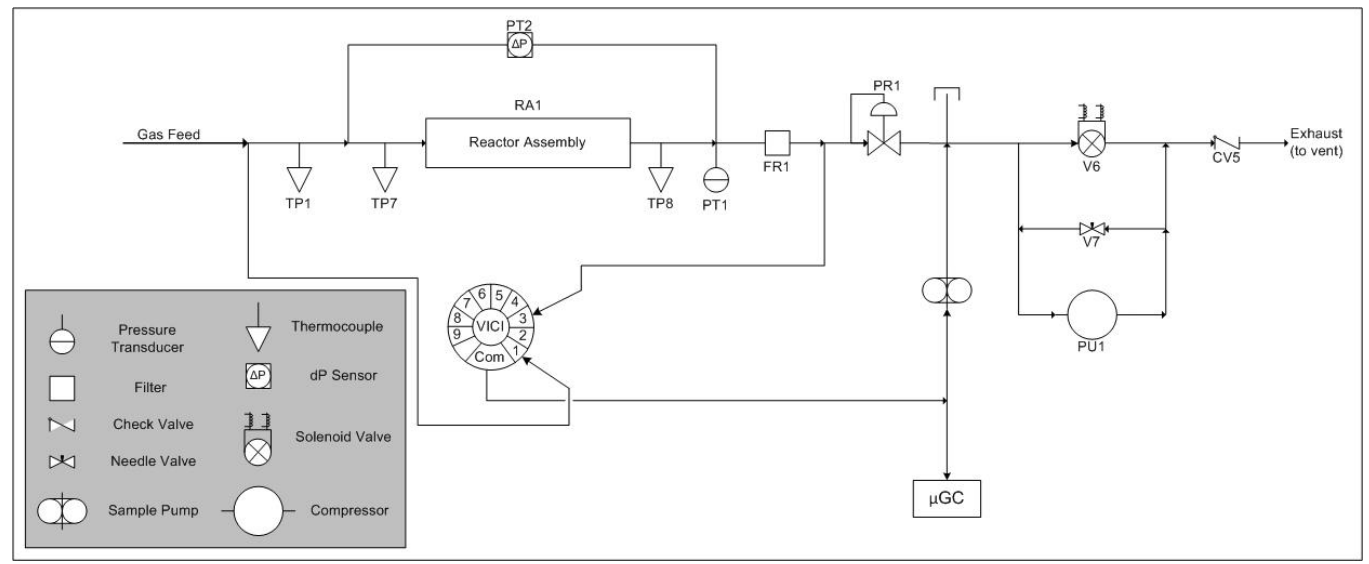

Figure 4. Schematic of Bosch Catalyst Test Stand as originally designed.

Once B-CaTS testing was completed, the system was modified into the Series B-CaTS as shown schematically in Figure 5. The new system is composed of the same basic hardware as the B-CaTS but includes a dual reactor assembly plumbed in series. The reactor orientation was changed from a horizontal configuration to a vertical configuration for two reasons: to maximize use of available space and to avoid catalyst settling. Condenser/separators were added at the outlets of each reactor for basic water removal. Finally, a sorbent bed containing 5A zeolite was installed between the reactors to remove unreacted $\mathrm{CO}_{2}$ and residual water. The original B-CaTS and the Series B-CaTS are shown for comparison in Figure 6 and Figure 7, respectively.

\section{B. Materials}

Materials used in testing included test gases and catalysts. All gases were purchased from A-Z Supply (Huntsville, AL). A total of eleven catalysts, identified in Table 2, were tested. Results from the testing of six of these catalysts, including a nickel foam (NiF-A), nickel on an aluminum support (Ni-Al), cobalt on an aluminum support (Co-Al), a nickel wool (NiW-B), and two steel wools (SW-S and SW-W) were reported in 2010. ${ }^{9}$ Additional information on these catalysts can be found in the reference and will not be described here. The remaining five catalysts include a nickel foam with slightly larger pore size (NiF-B) than that reported in 2010, nickel on a copper support ( $\mathrm{Ni}-\mathrm{Cu}$ ), a nickel wool (NiW-A), and nickel and cobalt shavings from pure metal rods (Ni-Sh and Co-Sh, respectively).

Nickel foam-B was prepared in identical fashion to NiF-A. Sheets of the foam were purchased from Novamet Specialty Products Corporation (Wyckoff, NJ). For each trial disks of approximately $4.5 \mathrm{~cm}$ diameter were cut from the foam. The catalyst mass varied by test. 


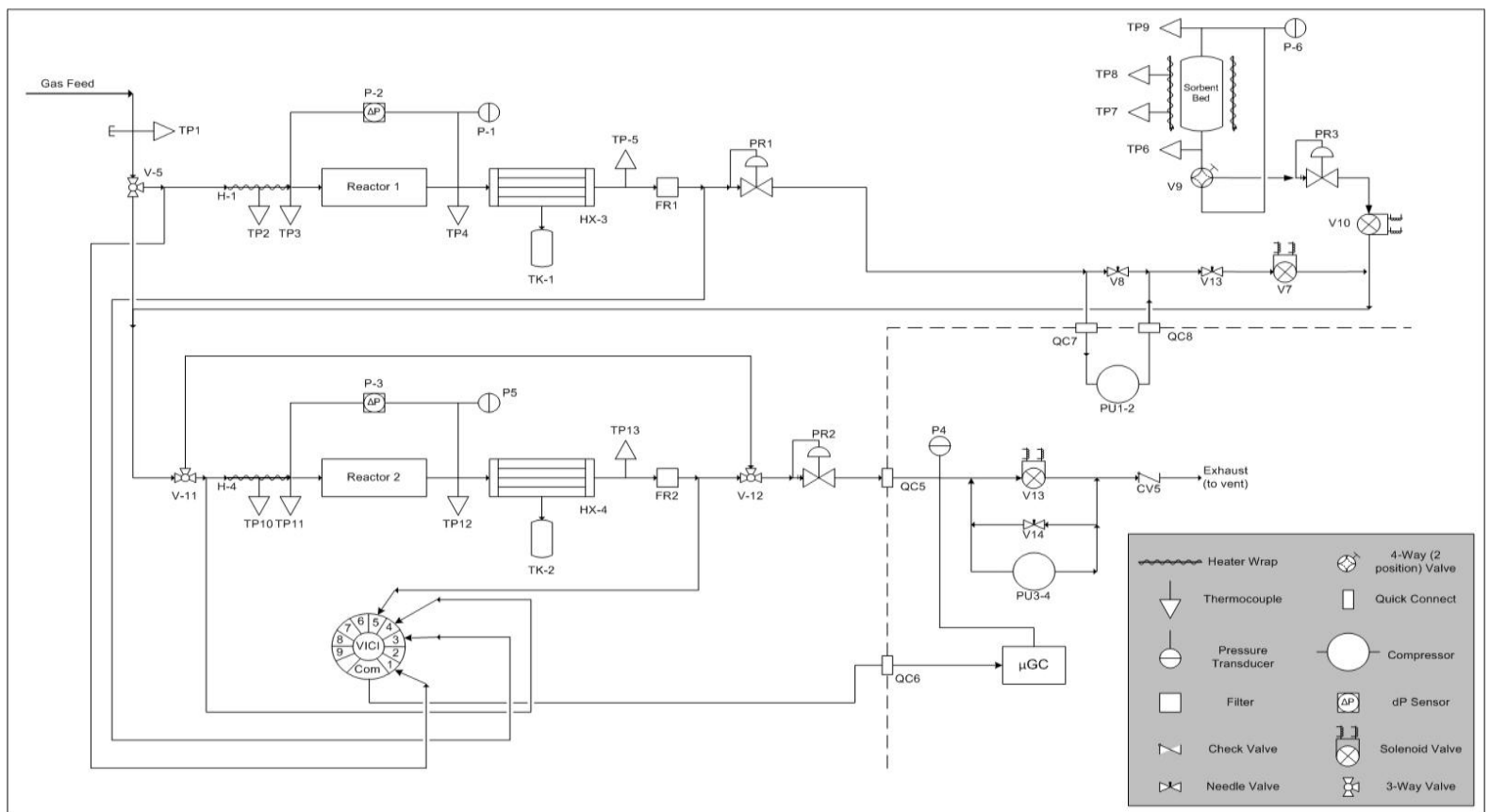

Figure 5. Schematic of Series-Bosch Catalyst Test Stand.

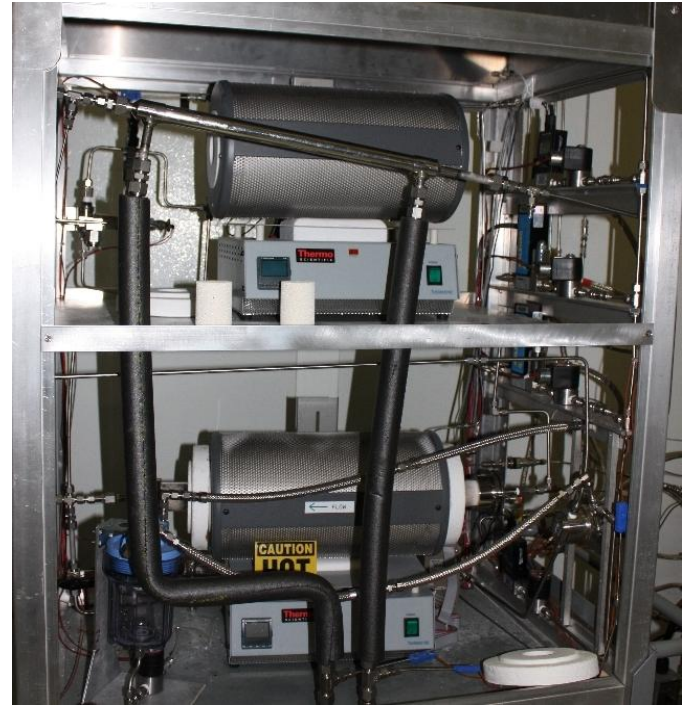

Figure 6. Bosch Catalyst Test Stand. Although shown with two reactors, only the bottom reactor was operational in the system.

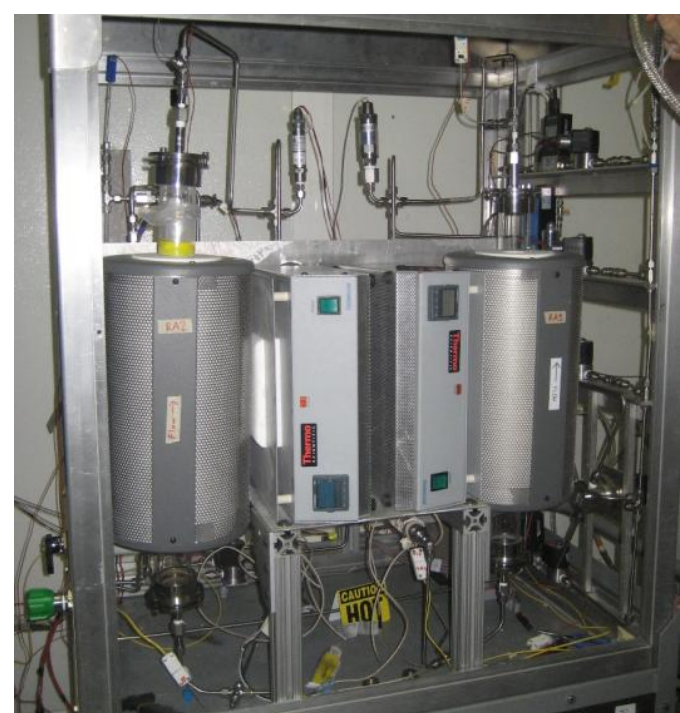

Figure 7. Series Bosch Catalyst Test Stand. The reactor assemblies were installed in series with optional bypass of the second reactor for singlereactor operation.

The Ni-Cu catalyst, shown in Figure 8, was prepared by plating nickel on a copper support using an ElectrolessNickel Plating Kit from Caswell Plating (Lyons, NY). The catalyst was stored under nitrogen until ready for testing and used within 24 hours of preparation. Total mass of the catalyst used for testing varied between $78-90$ grams. 
Table 2. Description of catalysts tested during Alternative Catalyst Screening Test.

\begin{tabular}{|c|c|c|c|}
\hline $\begin{array}{l}\text { Catalyst } \\
\text { Name }\end{array}$ & Catalyst Type & Description & Source \\
\hline $\mathrm{Co}-\mathrm{Al}$ & $\begin{array}{l}\text { Deposited } \\
\text { Cobalt }\end{array}$ & $\begin{array}{l}\text { Co on } \mathrm{Al} \\
\text { support }\end{array}$ & $\begin{array}{l}\text { Aluminum from ERG Materials and Aerospace Co. 10ppi, 9- } \\
11 \% \text { density, } 6101-\mathrm{T} 6 \text { or -F, Co from Caswell }\end{array}$ \\
\hline Co-Sh & Pure Cobalt & $\begin{array}{l}\text { shavings from a } \\
\text { cobalt rod }\end{array}$ & ESPI Metals solid cobalt rod 3N5 purity \\
\hline $\mathrm{Ni}-\mathrm{Al}$ & $\begin{array}{l}\text { Deposited } \\
\text { Nickel }\end{array}$ & $\begin{array}{c}\text { Ni on } \mathrm{Al} \\
\text { support }\end{array}$ & $\begin{array}{l}\text { Aluminum from ERG Materials and Aerospace Co. 10ppi, 9- } \\
11 \% \text { density, 6101-T6 or -F, Ni from Caswell }\end{array}$ \\
\hline $\mathrm{Ni}-\mathrm{Cu}$ & $\begin{array}{l}\text { Deposited } \\
\text { Nickel }\end{array}$ & $\begin{array}{c}\mathrm{Ni} \text { on } \mathrm{Cu} \\
\text { support }\end{array}$ & $\begin{array}{l}\text { Copper from ERG Materials and Aerospace Co. 10ppi, 9- } \\
11 \% \text { density, C10100, Ni from Caswell }\end{array}$ \\
\hline $\mathrm{NiF}-\mathrm{A}$ & Nickel Foam & small pore & Inco nickel foam, $590 \mathrm{um}$ pore size, $420 \mathrm{~g} / \mathrm{m}^{\wedge} 2$ \\
\hline NiF-B & Nickel Foam & large pore & Inco nickel foam, $800 \mathrm{um}$ pore size, $420 \mathrm{~g} / \mathrm{m}^{\wedge} 2$ \\
\hline $\mathrm{Ni}-\mathrm{Sh}$ & Pure Nickel & $\begin{array}{l}\text { shavings from a } \\
\text { nickel rod }\end{array}$ & ESPI Metals solid nickel rod 3N5 purity \\
\hline NiW-A & Nickel Wool & new & Intramicron 200 nickel fiber \\
\hline NiW-B & Nickel Wool & V-Bosch & V-Bosch cartridges \\
\hline SW-S & Steel Wool & shredded & Global Material Technologies, 4/0 Chopped Fiber 1/8"-1/4" \\
\hline SW-W & Steel Wool & wound & Global Material Technologies, 4/0 Reel 5lb \\
\hline
\end{tabular}

The NiW-A, shown in Figure 9, was purchased from IntraMicron (Auburn, AL) and used as received. Approximately 14 grams of catalyst was used in each test.

Nickel and cobalt shavings, shown in Figure 10 and Figure 11, were prepared from 99.9\% pure metal rods purchased from ESPI Metals (Ashland, OR). The rods were turned on a lathe while a cutting tool removed a layer of material approximately $0.127 \mathrm{~mm}(0.005$ ”) thick. During cutting, material broke off at semi-regular intervals to form the shavings. The cobalt shaving particles tended to be shorter, while the nickel shaving particles tended to form longer strands.

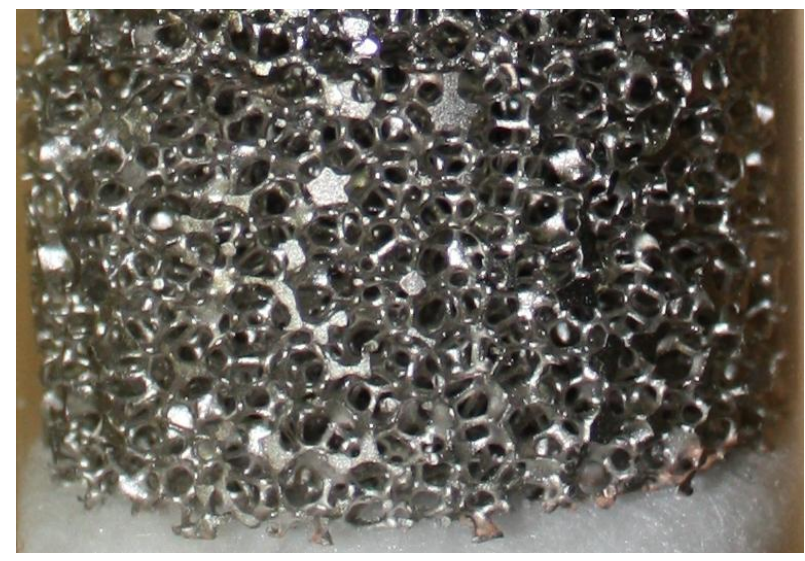

Figure 8. Copper support coated with nickel (Ni-Cu).

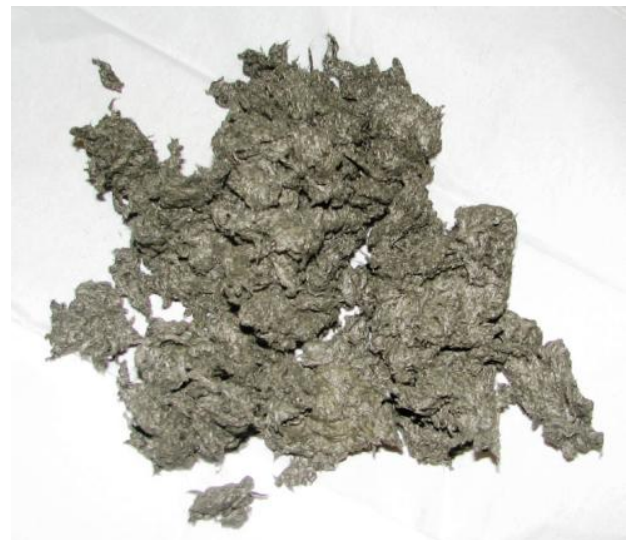

Figure 9. IntraMicron nickel wool (NiW-A). 


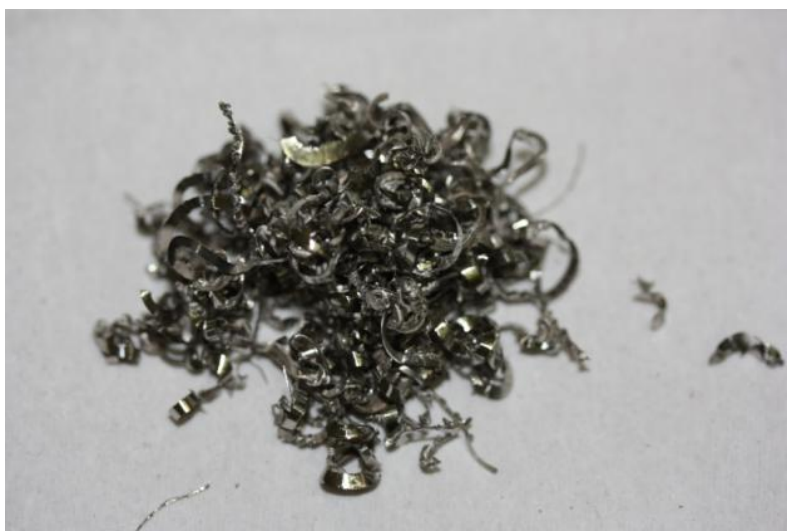

Figure 10. Nickel shavings from solid nickel rod (Ni-Sh).

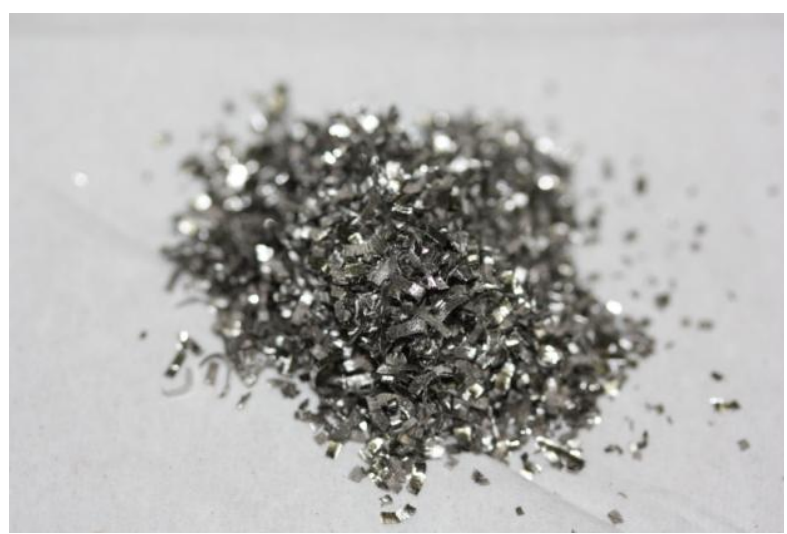

Figure 11. Cobalt shavings from solid cobalt rod (Co-Sh).

\section{Test Methods}

A total of four tests were completed to explore the possibility of developing a series-Bosch reactor system. These included the Alternative Catalyst Screening, the RWGS Equilibrium Evaluation, the Carbon Packing Density Test, and the Initial Series-Reactor Test. The methods for each test are detailed below.

\section{Alternative Catalyst Screening}

The Alternative Catalyst Screening Test was conducted in the B-CaTS to explore catalysts other than steel wool for the Bosch process. Catalysts were packed into quartz tubes (inner diameter $=2$ ") to a total volume of $\sim 5.08 \mathrm{in}^{3}\left(83.3 \mathrm{~cm}^{3}\right)$, as shown in Figure 12. This resulted in varied masses of catalysts for each test. Table 3 shows each catalyst and the average weight used in the Alternative Catalyst Screening Test. Insulation was placed on either side of the catalyst to contain the catalyst and any carbon that might have formed.

Once installed in the reactor assembly, catalysts were deoxidized with a constant 1:1 flow of nitrogen:hydrogen for one hour. For testing, catalysts were exposed to gas mixtures targeting one of the Bosch component

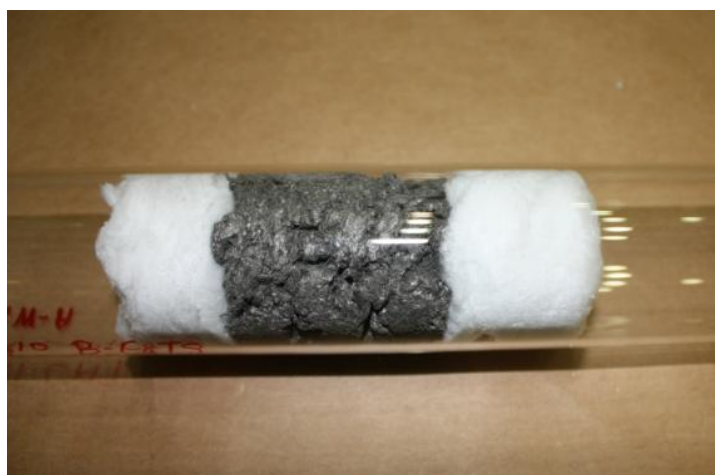

Figure 12. NiW-A catalyst packed into quartz reactor tube for Alternative Catalyst Screening Test.
Table 3. Average weight of catalysts necessary to fill $\sim 5.08 \mathrm{in}^{3}\left(83.3 \mathrm{~cm}^{3}\right)$ of reactor volume in the Alternative Catalyst Screening Test.

\begin{tabular}{|c|c|}
\hline Catalyst & $\begin{array}{c}\text { A verage Weight of } \\
\text { Catalyst }(\mathbf{g})\end{array}$ \\
\hline $\mathrm{Co}-\mathrm{Al}$ & 24.40 \\
\hline $\mathrm{Co}-\mathrm{Sh}$ & 30.03 \\
\hline $\mathrm{Ni}-\mathrm{Al}$ & 30.93 \\
\hline $\mathrm{Ni}-\mathrm{Cu}$ & 84.54 \\
\hline $\mathrm{NiF}-\mathrm{A}$ & 13.95 \\
\hline $\mathrm{NiF}-\mathrm{B}$ & 14.80 \\
\hline $\mathrm{Ni}-\mathrm{Sh}$ & 40.05 \\
\hline $\mathrm{NiW}-\mathrm{A}$ & 21.28 \\
\hline $\mathrm{NiW}-\mathrm{B}$ & 17.19 \\
\hline $\mathrm{SW}-\mathrm{S}$ & 8.03 \\
\hline $\mathrm{SW}-\mathrm{W}$ & 8.01 \\
\hline
\end{tabular}
reactions. A total flow rate of 200 SmLPM was used for each test. Nitrogen was used as a carrier gas for all trials. For RWGS testing, hydrogento-carbon dioxide ratios were varied from 0.2 to 5.0 at temperatures from $200^{\circ} \mathrm{C}$ to $650^{\circ} \mathrm{C}\left(392^{\circ} \mathrm{F}\right.$ to $\left.1200^{\circ} \mathrm{F}\right)$. For $\mathrm{CO}$ hydrogenation testing, hydrogen-tocarbon monoxide ratios were varied from 0.2 to 4.8 at temperatures from $200^{\circ} \mathrm{C}$ to $650^{\circ} \mathrm{C}\left(392^{\circ} \mathrm{F}\right.$ to $\left.1200^{\circ} \mathrm{F}\right)$. Finally, for Boudouard testing, $\mathrm{CO}$ was varied from 20 to $100 \%$ of the feed.

\section{RWGS Equilibrium Evaluation}

The RWGS Equilibrium Evaluation, conducted in the B-CaTS, explored equilibrium concentrations of the RWGS using four catalysts: Co-Sh, NiF-A, Ni-Sh, and SW-W. Reactor assemblies were prepared identically to those in the Alternative Catalyst Screening with the exception of the quantity of catalyst used. In an attempt to observe true equilibrium, the length of the catalyst bed was incrementally increased until no change in steady-state 
product concentration was observed. The reactor was fed hydrogen-to- $\mathrm{CO}_{2}$ ratios of $0.4,0.6$, and 0.8 at temperatures of $600^{\circ} \mathrm{C}, 650^{\circ} \mathrm{C}$, and $700^{\circ} \mathrm{C}$. Each run was completed with a total flow rate of $200 \mathrm{SmLPM}$ including $20 \mathrm{SmLPM}$ of nitrogen as a carrier gas.

\section{Specific Carbon Capacity Test}

The Specific Carbon Capacity Test, conducted in a single reactor of the Series-B-CaTS, was designed to explore the maximum carbon loading of three catalyts including SW-W, Ni-Sh, and Co-Sh. Prior testing in a full scale reactor with SW-W indicated a specific carbon capacity of greater than $23 \mathrm{~g}$ of carbon per $\mathrm{g}$ of catalyst. Reactor assemblies were prepared identically to those in the Alternative Catalyst Screening with the exception that minimal catalyst masses were utilized in order to shorten the test time. Each catalyst was exposed to a feed stream containing hydrogen and carbon monoxide in a molar ratio of 1-to- 1 at a temperature of $500^{\circ} \mathrm{C}$ and at a pressure of $103 \mathrm{kPa}$ $(15.0 \mathrm{psi})$ in order to observe variations in reactor performance with increasing carbon accumulation. The test was concluded when the rate of carbon formation was roughly unchanged over 2-3 hours of testing.

\section{Results and Discussion}

A total of four tests were conducted to explore the potential of developing an improved Bosch reactor for oxygen recovery. The results of each test and a discussion of the results are provided below.

\section{A. Alternative Catalyst Screening Evaluation}

Traditional Bosch operation involved the use of steel wool as a catalyst. Because of high temperature operation, low single-pass efficiency, and high resupply requirements of the traditional reactor, alternative catalysts are of interest. The purpose of the Alternative Catalyst Screening Evaluation was to explore catalysts other than steel wool with the intention of using one or more catalysts in a multi-stage Bosch reactor system. A total of eleven catalysts were evaluated for their performance in catalyzing three reactions: RWGS reaction, Boudouard reaction, and CO hydrogenation reaction. Due to the nature of NASA missions, minimization of mass and volume are both high priorities for any development effort. For this reason, reaction rate data will be presented as a function of both catalyst mass and catalyst volume.

In a series-Bosch reactor system, the RWGS reaction will be carried out in the first stage. The traditional Bosch reactor was operated at $\sim 650^{\circ} \mathrm{C}$. However, it is highly desirable for a replacement system to operate at lower temperatures to reduce power requirements. Figure 13 and Figure 14 show the comparative RWGS reaction rates for all eleven catalysts at an $\mathrm{H}_{2}: \mathrm{CO}_{2}$ feed ratio of 0.8 and a temperature of $500^{\circ} \mathrm{C}$. From Figure 13, it is clear that on a mass basis, NiF-A is the best option for the RWGS reaction at $500^{\circ} \mathrm{C}$. Ni-Sh, Co-Sh, and steel wool all exhibited similar reaction rates. However, on a volume basis, as shown in Figure 14, Co-Sh and Ni-Sh showed performance much closer to the NiF-A.

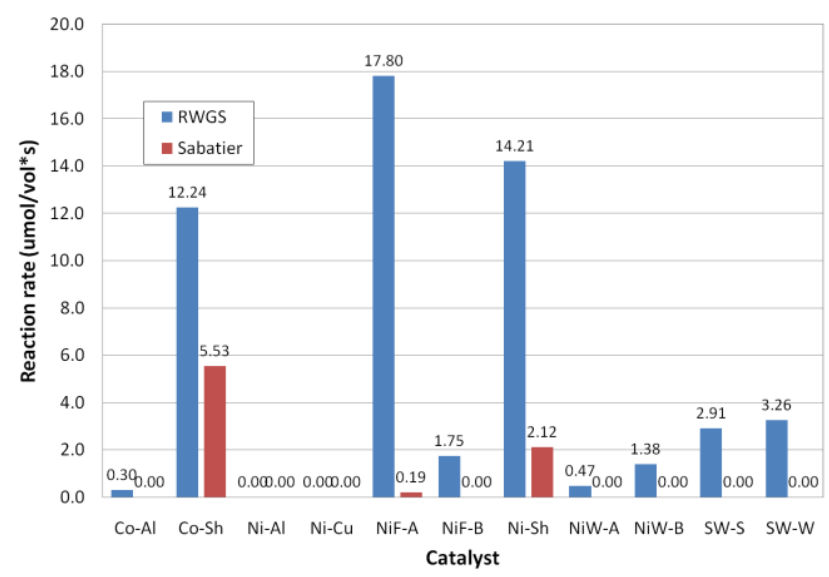

Figure 13. Rate of reaction per mass of catalyst of $\mathrm{CO}_{2}$ at $500^{\circ} \mathrm{C}$ and $\mathrm{H}_{2}: \mathrm{CO}_{2}=0.8$.

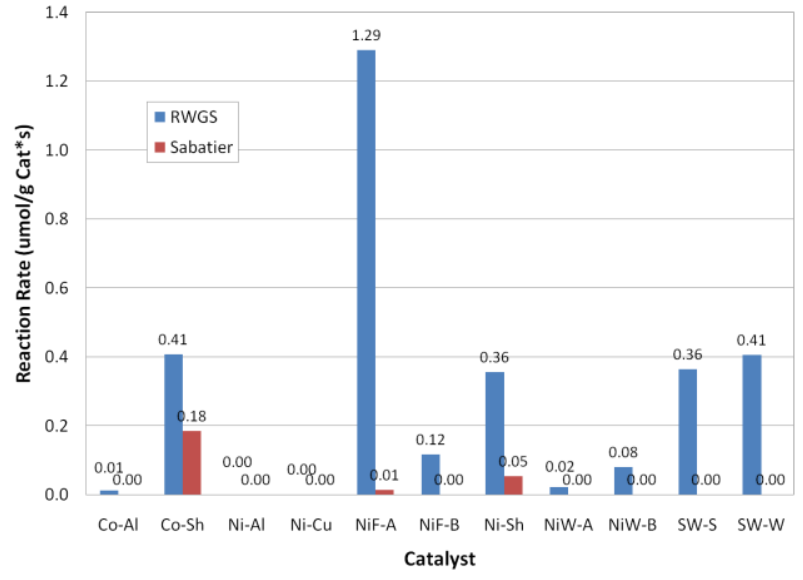

Figure 14. Rate of reaction per volume of catalyst of $\mathrm{CO}_{2}$ at $500^{\circ} \mathrm{C}$ and $\mathrm{H}_{2}: \mathrm{CO}_{2}=0.8$.

Relative selectivity, another key factor of interest, can also be gathered from these figures. Conversion of $\mathrm{CO}_{2}$ to methane via the Sabatier reaction is an unwanted side-reaction shown to be most prevalent with Co-Sh and Ni-Sh catalysts. Higher temperature operation of the reactor would limit or eliminate methane production, but again require 
more power than desirable. Thus, despite anticipated methane production and based on the data shown above, CoSh, Ni-Sh, and NiF-A were chosen for advanced RWGS testing. SW-W was also chosen for follow-on testing as a baseline comparison.

The second stage of a series-Bosch reactor system will be a carbon formation reactor. The Alternative Catalyst Screening Evaluation attempted to explore carbon formation from either the CO hydrogenation reaction or the Boudouard reaction. Analysis of the Boudouard reaction rates was straight-forward. However, due to the feed gases for the CO hydrogenation reaction, three separate reactions were possible: CO hydrogenation, Boudouard, or Sabatier. Data analysis confirmed that all three reactions often occurred on a given catalyst. Figure 15 and Figure 16 show total carbon formation rates (from both Boudouard and CO hydrogenation reactions) compared to the rate of methane formation (from the Sabatier reaction) when $\mathrm{CO}$ and hydrogen were fed to the reactor assembly. On a per mass basis, it is clear that the steel wools produce the most carbon. However, if a per volume basis is used, Co-Sh and $\mathrm{Ni}$-Sh also show significant carbon formation at the given temperature and feed composition.

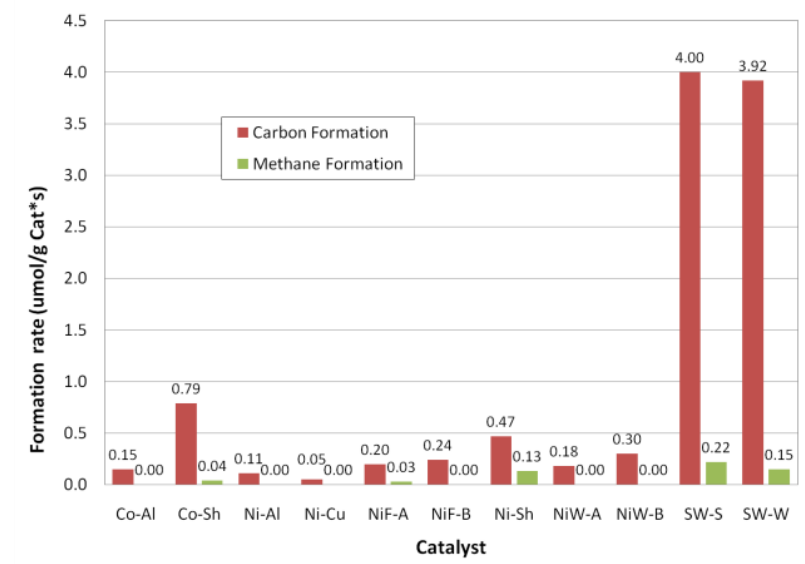

Figure 15. Carbon formation versus methane formation per catalyst mass in $\mathrm{CO}$ hydrogenation testing at $500^{\circ} \mathrm{C}$ and $\mathrm{H}_{2}: \mathrm{CO}=1.33$.

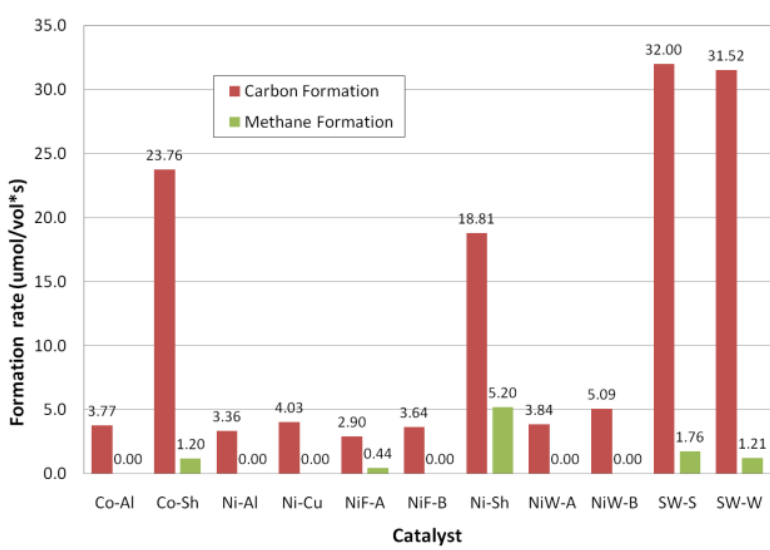

Figure 16. Carbon formation versus methane formation per volume in $\mathrm{CO}$ hydrogenation testing at $500^{\circ} \mathrm{C}$ and $\mathrm{H}_{2}: \mathrm{CO}=1.33$.

Of particular interest was the fact that the Boudouard reaction occurred more readily in the presence of hydrogen than when only $\mathrm{CO}$ was available, as shown in Figure 17 and Figure 18. A more thorough discussion of this phenomenon is available elsewhere. ${ }^{9}$ It is clear that the feed stream to a second stage for a series-Bosch reactor must include hydrogen in order to achieve acceptable carbon deposition rates. Unfortunately, this increases the possibility of a Sabatier side-reaction producing unwanted methane. Of the four catalysts shown to have potential as a carbon formation catalyst (Co-Sh, Ni-Sh, SW-S, and $\mathrm{SW}$ W), all four also show methane production. Despite these concerns, Co-Sh, Ni-Sh, and SW-W were chosen for further analysis in a series-Bosch reactor system.

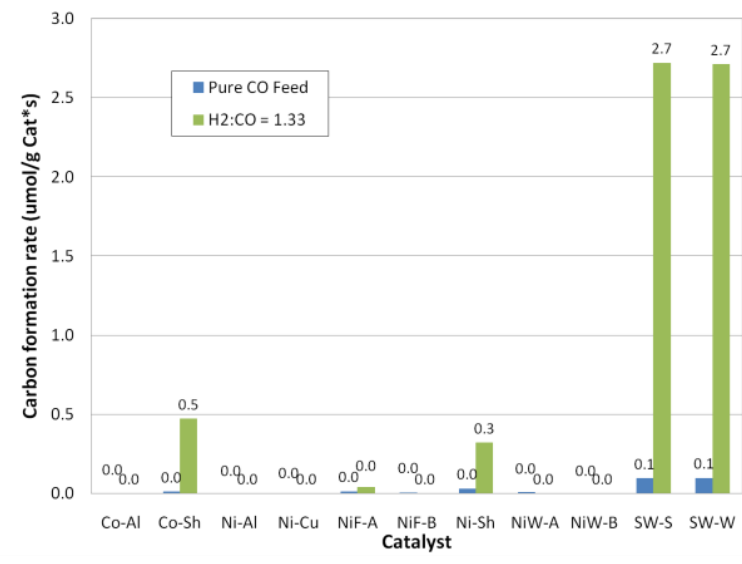

Figure 17. Boudouard reaction per mass from both a pure $\mathrm{CO}$ feed and a $\mathrm{CO} / \mathrm{H}_{2}$ feed at $500^{\circ} \mathrm{C}$.

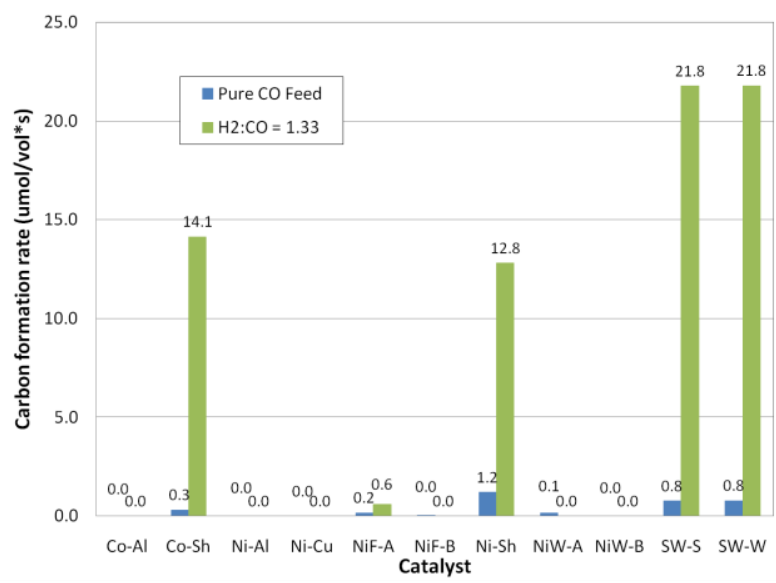

Figure 18. Boudouard reaction per volume from both a pure $\mathrm{CO}$ feed and a $\mathrm{CO} / \mathrm{H} 2$ feed at $500^{\circ} \mathrm{C}$.

American Institute of Aeronautics and Astronautics 


\section{B. RWGS Equilibrium Evaluation}

Following the Alternative Catalyst Screening Evaluation, it was clear that Co-Sh, Ni-Sh, and NiF-A should be evaluated further as potential catalysts for the first stage of a series-Bosch reactor system. SW-W was also chosen for further analysis as a baseline. In order to design a RWGS reactor, a complete rate equation will be required. Based on the stoichiometry of the RWGS reaction, the equlibrium constant can be written as shown below.

$$
\begin{aligned}
\mathrm{CO}_{2}+\mathrm{H}_{2} \leftrightarrow \mathrm{H}_{2} \mathrm{O}+\mathrm{CO} \\
K_{R W G S}=\frac{P_{\mathrm{H}_{2} \mathrm{O}} P_{\mathrm{CO}}}{P_{\mathrm{CO}_{2}} P_{\mathrm{H}_{2}}}
\end{aligned}
$$

(RWGS Reaction)

(RWGS Equilibrium Constant)

It has been shown that methane is also a product of a Bosch system. This is particularly true at lower temperatures due to the Sabatier reaction as written below.

$$
\mathrm{CO}_{2}+\mathrm{H}_{2} \leftrightarrow \mathrm{CH}_{4}+2 \mathrm{H}_{2} \mathrm{O}
$$

(Sabatier Reaction)

With an equilibrium constant defined as:

$$
K_{\mathrm{Sab}}=\frac{P_{\mathrm{H}_{2} \mathrm{O}}^{2} P_{\mathrm{CH}_{4}}}{P_{\mathrm{CO}_{2}} P_{\mathrm{H}_{2}}^{4}}
$$

(Sabatier Equilibrium Constant)

Multireaction equilibria often requires numerical analysis to determine theoretical equilibrium compositions. ${ }^{10}$ This was completed for the RWGS and Sabatier reactions to determine theoretical composition of the system at the relevant temperatures. From this data, theoretical extents of reaction were also determined. Extent of reaction is defined as the quantity of reacted $\mathrm{CO}_{2}$ for each reaction $(\mathrm{mmol} / \mathrm{min})$. The observed extent of reaction in testing is compared with the theoretical extents of reactions for both multireaction and RWGS below. Figure 19, Figure 20, and Figure 21 show theoretical and empirical data for $\mathrm{H}_{2}: \mathrm{CO}_{2}$ feeds of $0.4,0.6$, and 0.8 , respectively. At feed $\mathrm{H}_{2}: \mathrm{CO}_{2}$ ratios of 0.6 and 0.8 , all catalysts, with the exception of steel wool, resulted in compositions very close to the theoretical for a multireaction system, indicating that the systems were very near equilibrium. Steel wool showed very low extents of reaction at all feed ratios. This is most likely due to a much lower rate of reaction over steel wool as compared to the cobalt and nickel catalysts. Thus, for a similar residence time, the reaction was not able to

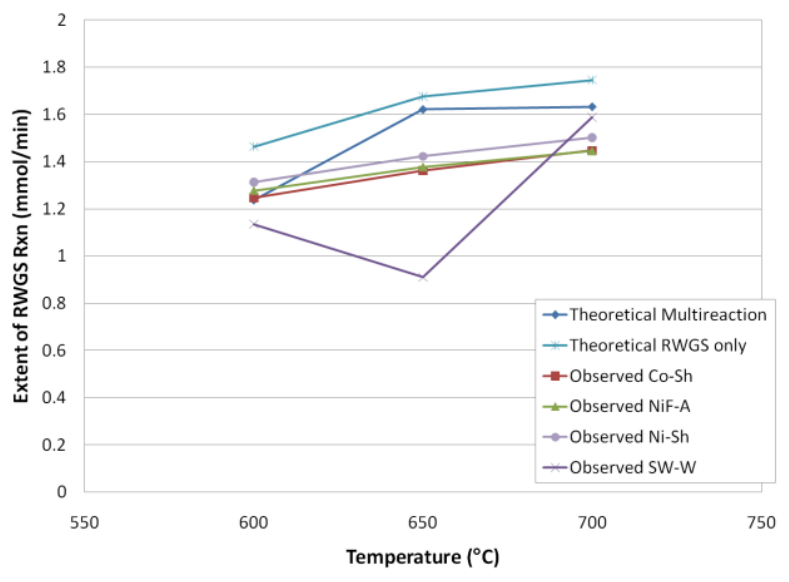

Figure 19. Equilibrium composition of RWGS/Sabatier system at $\mathrm{H}_{2}: \mathrm{CO}_{2}$ feed of $\mathbf{0 . 4}$. Observed and theoretical values are shown for comparison.

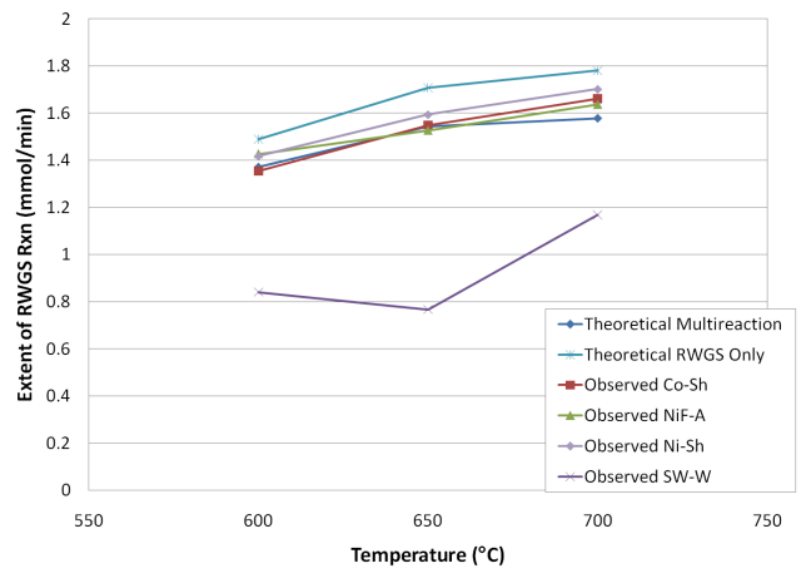

Figure 20. Equilibrium composition of RWGS/Sabatier system at $\mathrm{H}_{2}: \mathbf{C O}_{2}$ feed of $\mathbf{0 . 6}$. Observed and theoretical values are shown for comparison. 
reach equilibrium. Additionally, steel wool showed a similar trend with respect to temperature for all feed ratios. The data indicated significantly lower extent of reaction at $650{ }^{\circ} \mathrm{C}$ than the other temperatures. While this might otherwise be assumed to be due to excessive methane formation, this is not the case for steel wool where no methane was observed. In fact, if the reaction rates were sufficient to reach equilibrium with the given residence time, the system should reach the single reaction equilibrium line.

From the data collected in the RWGS Equilibrium evaluation, it is clear that steel wool will not be acceptable as a RWGS catalyst. However, NiF-A, Ni-Sh, or Co-Sh have potential in future testing in addition to commercially available catalysts for this purpose. Furthermore, conversion is theoretically higher at lower pressures for a given $\mathrm{H}_{2}: \mathrm{CO}_{2}$ feed ratio as shown in Figure 22. Designing a first stage Bosch reactor to operate at sub-ambient pressures

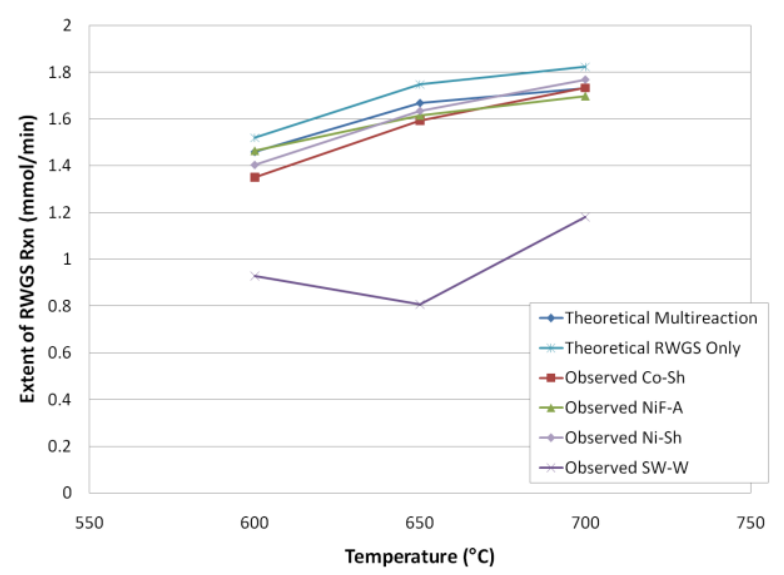

Figure 21. Equilibrium composition of RWGS/Sabatier system at $\mathrm{H}_{2}: \mathrm{CO}_{2}$ feed of 0.8 . Observed and theoretical values are shown for comparison.

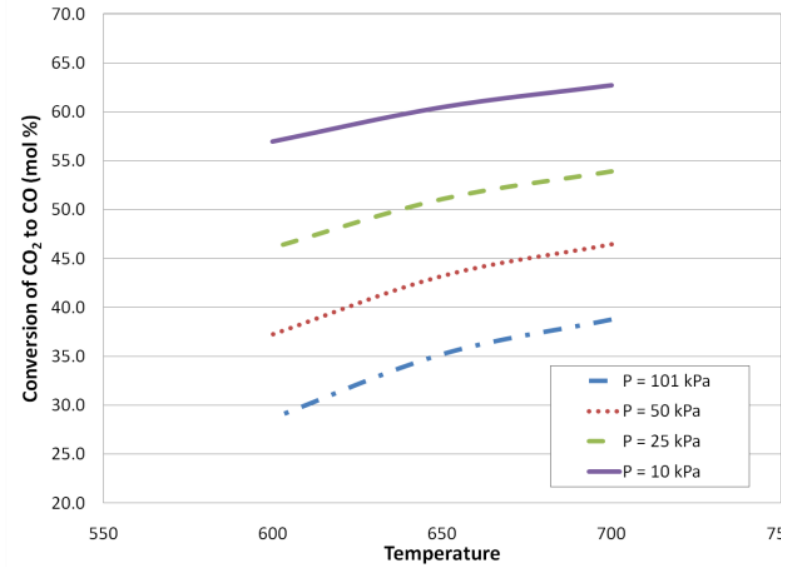

Figure 22. Theoretical equilibrium conversion at multiple pressures and temperatures.

will provide two benefits. First, equilibrium conversion can be expected to be greater at sub-ambient than traditional operation pressure ( 28 psia). This will improve the Bosch, provided the decrease in reaction rate due to lower partial pressures can be overcome. Second, previous developmental Bosch reactors operating at above-ambient conditions required external containment to mitigate the hazard of leaking hydrogen or carbon monoxide into the cabin environment. This ultimately added to the overall mass and volume of the system. Thus, operation at subambient pressure will decrease the system mass and volume and reduce risk in flight application.

\section{Specific Carbon Capacity Test}

Three catalysts were tested to determine the maximum specific carbon capacity of each at $500^{\circ} \mathrm{C}$. A comparison of these catalyts can be seen in Figure 23. The first three groupings of bars show the relative quantity of $\mathrm{CO}$ that was converted to methane, to carbon via the Boudouard (Boud) reaction, and to carbon via the Hydrogenation (Hydro) reaction, respectively. The final two groupings of bars show the fractional conversion of $\mathrm{CO}$ overall and to carbon, respectively. As seen from the graph, there was no statistical difference between $\mathrm{Ni}-\mathrm{Sh}$ and Co-Sh for any of the metrics described. Of more importance is the fact that the steel wool catalyst was significantly better than either of the other catalysts at forming carbon. It is clear from this data, that steel wool continues to be the first choice for carbon formation catalyst among the catalysts tested thus far, despite the formation of significant quantities of methane. Therefore,

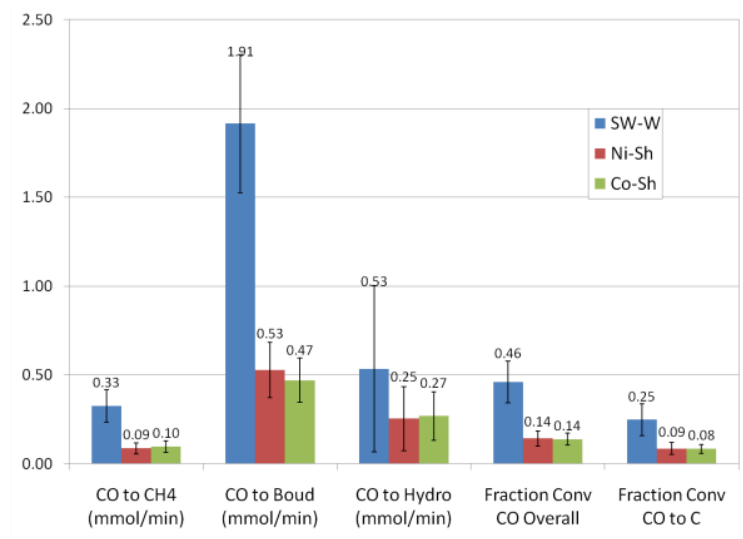

Figure 23. Comparison of catalyst performance in Carbon Formation Test. specifics of the Ni-Sh and Co-Sh testing will not be discussed. For testing with SW-W, the system initially began 
with a total of $1.03 \mathrm{~g}$ of SW-W and carbon monoxide feed of $4 \mathrm{mmol} / \mathrm{min}$. Steady carbon formation was observed immediately, as shown in Figure 24. In an attempt to increase the rate of carbon formation, the flow rate of carbon (in the form of carbon monoxide) was doubled after $\sim 190$ minutes. Although the carbon formation rate did increase, pressure drop in the system also began to increase. After $\sim 375$ minutes, the carbon monoxide feed rate was lowered to $6 \mathrm{mmol} / \mathrm{min}$ where it remained for the rest of the test. Despite this drop in flow rate, the pressure drop across the bed continued to increase, indicating significant carbon formation within the reactor. After $\sim 850$ minutes of operation time, the pressure drop across the reactor exceeded $12 \mathrm{psid}$, at which point the test was paused. Data indicated a total carbon deposition of $23.95 \mathrm{~g}$ carbon per gram catalyst at

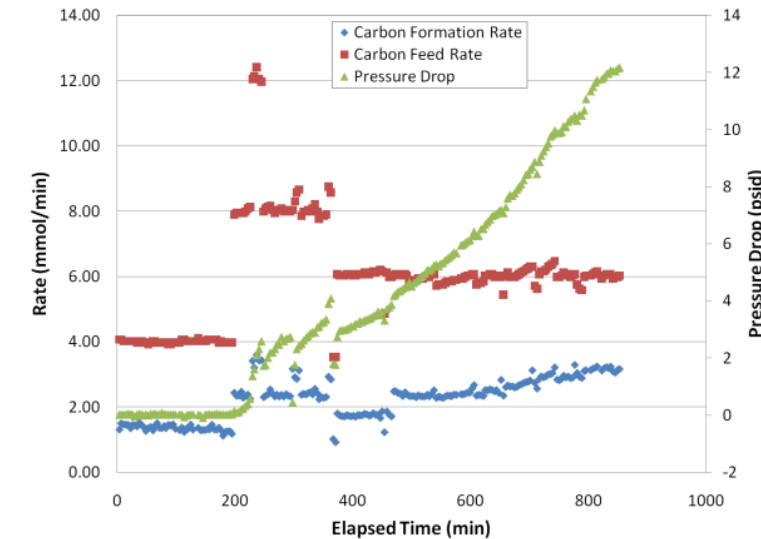

Figure 24. Carbon feed rate, carbon formation rate, and pressure drop for initial mass of catalyst. this point.

A $3.30 \mathrm{~g}$ portion of the catalyst containing product carbon was removed from the reactor and used to seed a new bed. Based on the mean specific carbon deposition of the catalyst at the time of re-seeding, it was determined that $0.14 \mathrm{~g}$ of catalyst with $3.16 \mathrm{~g}$ of carbon were packed into the new bed. Once re-seeded, the test was restarted as shown in Figure 25. The rate of carbon formation was shown to decrease only slightly over the next 1600 minutes of testing. Additionally, the pressure drop across the bed remained nearly zero. As expected, carbon accumulated more quickly with a larger quantity of catalyst, as shown in Figure 26. However, the difference in rate was not directly proportional to the difference in available catalyst mass.

The end of the test was determined by available time rather than exhaustion of catalyst. However, at the completion of testing, total specific carbon density was $\sim 207 \mathrm{~g}$ carbon/g catalyst. This finding is critical to the design of future Bosch systems. Rather than transporting catalyst with the intention of replacing after a total carbon packing density of $23 \mathrm{~g} / \mathrm{g}$ catalyst, as previously designed, a system could anticipate greater than $200 \mathrm{~g}$ carbon/g catalyst if the hardware and operating methods were designed to tolerate the rate profiles shown in Figures 24-26. This could be accomplished in a number of ways. For example, re-seeding several catalyst cartridges from a single, used cartridge or simply placing less catalyst into each cartridge.

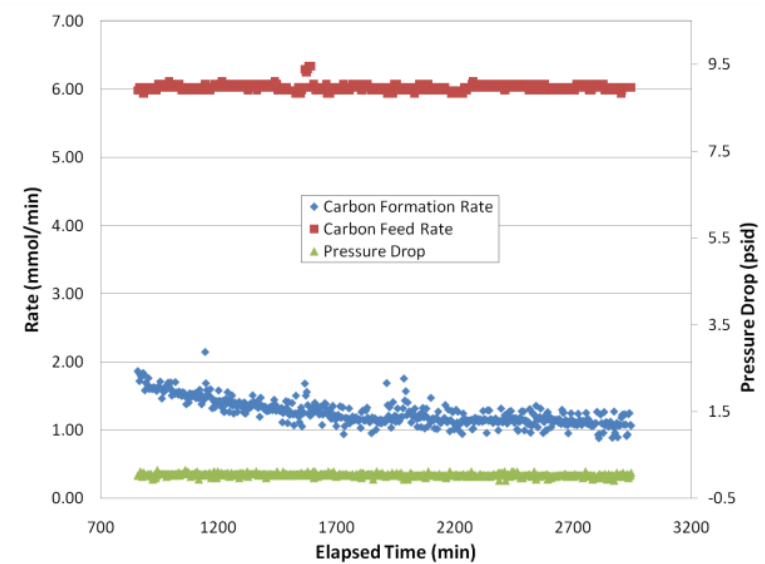

Figure 25. Carbon feed rate, carbon formation rate, and pressure drop for final mass of catalyst.

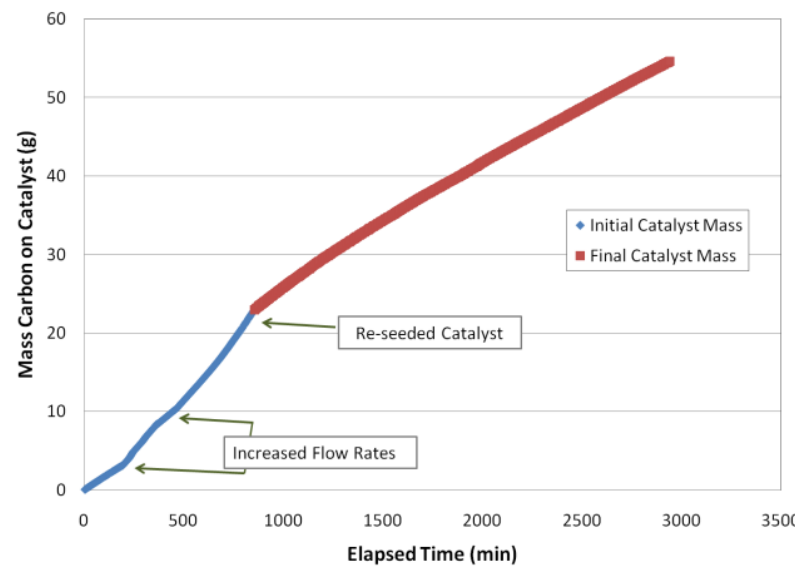

Figure 26. Carbon accumulation on SW-W for both initial and final masses of catalyst.

\section{Conclusion}

Although a total of eleven catalysts were tested for their activity toward the RWGS, CO hydrogenation and Boudouard reactions, only four showed promise as RWGS catalysts and only three showed promise as carbon formation catalysts. Testing of RWGS catalysts indicated the potential for significantly higher single-pass conversions than those reportedly observed in previous Bosch testing. Similarly, carbon formation testing of steel 
wool indicated significantly greater maximum specific carbon capacity than previously observed in Bosch testing. The results discussed herein provide substantial support for pursuing development of a series-Bosch reactor to maximize conversions, thereby reducing mass, volume and power requirements over previous generations of Bosch reactors.

\section{Acknowledgments}

The authors would like to acknowledge Tom Williams for software development of the B-CaTS and Series B-CaTS test stands. They would like to acknowledge Joseph Scott and Gena Gibbs-Dalton for their support in catalyst preparation and use of laboratory materials. They acknowledge Tony Mahathey and Curtis Leslie for their significant contribution to test stand modifications and daily testing. The authors would also like to extend a special thanks to Dr. Jeffrey Weimer at the University of Alabama-Huntsville for lessons in thermodynamics.

\section{References}

${ }^{1}$ Diamant, B.L., Humphries, W.R., "Past and Present Environmental Control and Life Support Systems on Manned Spacecraft," 20th Intersociety Conference on Environmental Systems, SAE Technical Paper 901210, Williamsburg, VA, 1990.

${ }^{2}$ Murdoch, K.E., Scull, T.D., Carrasquillo, R.L., Graf, J., "Sabatier CO2 Reduction System Design Status," 32nd International Conference on Environmental Systems, SAE Technical Paper 2002-01-2531, San Antonio, Texas, July 15-18, 2002.

${ }^{3}$ Murdoch, K., Perry, J., Smith, F., "Sabatier Engineering Development Unit," 33rd International Conference on Environmental Systems, SAE Technical Paper 2003-01-2496, Vancouver, B.C., Canada, July 7-10,2003.

${ }^{4}$ Knox, J.C., Campbell, M., Murdoch, K., Miller, L.A., Jeng, F., "Integrated Test and Evaluation of a 4-Bed Molecular Sieve (4BMS) Carbon Dioxide Removal System (CDRA), Mechanical Compressor Engineering Development Unit (EDU), and Sabatier Engineering Development Unit (EDU)," 35th International Conference on Environmental Systems, SAE Technical Paper 2005-01-2864, Rome, Italy, July 11-14, 2005.

${ }^{5}$ Knox, J.C., Miller, L.A., Luna, B., Campbell, M., "Integrated Test and Evaluation of a 4-Bed Molecular Sieve (4BMS) Carbon Dioxide Removal System (CDRA), Temperature Swing Adsorption Compressor (TSAC), and Sabatier Engineering Development Unit (EDU)," 36th International Conference on Environmental Systems, SAE Technical Paper 2006-01-2271, Norfolk, Virginia, July 17-20, 2006.

${ }^{6}$ Armstrong, R.C., "Life Support System For Space Flights of Extended Time Periods," NASA CR-614, General Dynamics, Life Support Project, Life Sciences Department, 1966.

${ }^{7}$ Holmes, R.F., Keller, E.E., King, C.D., "A Carbon Dioxide Reduction Unit Using Bosch Reaction and Expendable Catalyst Cartridges," NASA CR-1682, General Dynamics Corporation, Convair Division, 1970.

${ }^{8}$ Carrasquillo, R.L., Carter, D.L., Holder, D.W., McGriff, C.F., Ogle, K.Y., "Space Station Freedom Environmental Control and Life Support System Regenerative Subsystem Selection," NASA TM-4340, 1992.

${ }^{9}$ Abney, M.B., Mansell, J.M., "The Bosch Process - Performance of a Developmental Reactor and Experimental Evaluation of Alternative Catalysts," 40th Annual Conference on Environmental Systems, AIAA Technical Paper, AIAA-2010-6272, Barcelona, Spain, July 11-15, 2010.

${ }^{10}$ Smith, J.M., Van Ness, H.C., Abbott, M.M., Introduction to Chemical Engineering Thermodynamics, $6^{\text {th }}$ ed., McGraw-Hill, New York, 2001, Chap. 13. 